\title{
Methodology to Select the Best Business Game in Higher Education
}

\author{
María Romero Cuadrado ${ }^{1}$, Milagros Gutiérrez Fernández ${ }^{2}$ \\ ${ }^{1}$ Spanish Distance Learning University, Madrid, Spain; ${ }^{2}$ University of Extremadura, Extremadura, Spain. \\ Email:mromero@cee.uned.es,mgutierrezf@unex,es
}

Received October $4^{\text {th }}, 2013$; revised November $4^{\text {th }}$, 2013; accepted November $11^{\text {th }}, 2013$

Copyright (C 2013 María Romero Cuadrado, Milagros Gutiérrez Fernández. This is an open access article distributed under the Creative Commons Attribution License, which permits unrestricted use, distribution, and reproduction in any medium, provided the original work is properly cited.

\begin{abstract}
Business simulators are frequently used in higher education for its pedagogical importance. The purpose of this survey is to know the opinion of the faculty staff regarding certain aspects of the game they use in their teaching, using the Macbeth (Measuring Attractiveness by a Category Based Evaluation Technique) approach. This research is supported in the multi-criteria analysis to obtain a classification of several simulation games in the role of its educational features. The methodology establishes a hierarchical order that will allow determining the optimum simulator valuing its pedagogical efficiency.
\end{abstract}

Keywords: Higher Education; Business Games; Decision Making; Pedagogical Features; MACBETH

\section{Introduction}

Business games are frequently used in higher education for its pedagogical importance. Also its dynamism and competitiveness make them a credible learning method, reflecting reality, in which business decisions are affected, within many factors, for its competitors [1]. Such credibility will grow as the students see certain logic between their decisions and game results, taking a positive attitude towards the game.

In general, participants in a game become aware of the interrelation between an organization's main functions in a very realistic way; for example, the importance of merchandising in finance and production $[2,3]$. Such interrelation, much explained in theory is grasped quickly by the students thanks to the game. Therefore, it is about a learning method that students face with big interest and motivation, feeling "in" the simulation, stemming difficulties by keeping such excitement.

Simulation games are activities oriented towards a goal whose content and processes are intimately related with some general or specific competence, by means of the implementation of a series of instructions that participants must follow, for the game to be effective. Generally these rules are specified by the designer and presented to the participants as game instructions. The number and specification of the instructions change from one activity to another and from one game to the other.

A game to be educational has to meet a series of features. According to [4], games plausibility is essential for the students to consider it a real learning method and to be motivated by it. Nevertheless, they must understand that it's only a simplified representation of reality, and because of that, they should not operate it assuming all real life circumstances are taking place.

[3] upholds that to make the most of the results, the game must be capable of responding to showing expectations, with the objective of knowing if it has been useful to the participants, and if it has allowed the achievement of objectives to set a priori.

Also, it is important that the game makes it possible for the student to be creative at decision-making and makes it possible for the professor to intervene in the simulation while teaching, taking one direction or another [5]. To capture business reality, the game should be complex enough; although, it's necessary to take into account that an excessive game complexity causes frustration between participants. It is considered the optimum game that contains enough aspects for the student to try solving specific problems, and at the same time provides a general approach of what management is about, considering at all times that the student copes with an uncer- 
tain and competitive environment $[2,6]$.

In order to learn to be effective, it is essential that the student involves creatively and perseveres in the game, and the professor is constant in advice and in control of the students, providing continuous feedback [7].

The unlimited grade of realism of this simulation contributes to making evident that the ethical solution of business problems of international nature requires diagnostic capacity and conceptual reasoning superior to what management usually calls for in most cases; quailties that for another side certainly are developed by business games independently of their other possible merits.

Through the bibliographical revision made, this research expects to determine the business game with most pedagogical effectiveness, from a teaching approach, through the use of multi-criteria methodology "Measuring Attractiveness by a Category Based Evaluation Technique" (MACBETH). For this, we have considered the features that better describe a business simulator from a pedagogical approach: clarity in its instructions, creativity developed in students, grade of complexity, represented reality, fulfillment of the faculty educational objectives and the students expectations, and the grade shown in the interrelation between several business areas.

The rest of the features have been avoided for being considered hard to measure by a professor in an objective way, being more feasible to value by the student. This will open as a future line of research, similar studies from a student approach.

\section{Field Work}

Field work has taken place during the months of February, March and April of 2013. The information is gathered through a survey sent by e-mail to 300 college professors of several Spanish universities that implement business simulation games, using as support a questionnaire composed of 10 questions (See Annex 1). There were 130 surveys received, from which 17 were discarded for not completing the required fields correctly, leaving the sample object of study constituted by 113 professors, from the following universities: Deusto, Pompeu Fabra, Rey Juan Carlos, ICADE, Universidad de Valladolid, UNED, CEU San Pablo, ESIC, Universidad de Extremadura, Universidad de Jaen, Universidad de la Laguna and the Universidad Pública de Navarra.

The games used by the faculty of these universities are the following nine: International Operation Simulation (INTOP), Venture Game, Business Strategy Game 8.0, Directivo Game (Manager Game), Juego del Ejecutivo (Game of the Executive), Estratega Game (Strategist Game), International Operations Simulation Mark 2000 (INTOPIA), Global Marketing Competition, and Labo- ratorio de Gestion (Management Laboratory).

The purpose of this survey is to know the opinion of the faculty staff regarding certain aspects of the game that they use in their teaching. Considering the mean of the received responses for each game, and using the MACBETH approach, it will be possible to establish a hierarchical order that will allow determining the optimum simulator, between the ones considered, valuing its pedagogical efficiency.

\section{Analytical Procedure}

The methodology used in this research is supported in the multi-criteria analysis to obtain a classification of the simulation games mentioned previously (which act as classified alternatives), in role of its educational features (which act as criteria or variables to consider).

The selection made of a multi-criteria methodology is based in the existence of multiple criteria (features in this case), that have to be evaluated and classified from a uniform perspective. This way, the objective of the decider or evaluator (decision maker) will be to identify an alternative, in this case a simulation game that satisfies, in every way possible, all the selected criteria. Despite the previous, it should be emphasize that an absolute and valid "better solution" will not exist for all the decisionmakers, because the results of the multi-criteria problem will depend of the personal preferences of each one of the professors. Such preferences can be expressed in a quantitative or qualitative way, for the several existing methodologies for the processing of information.

The object of study provides quantitative information (expressed through rating scales) about the opinion of a group of Spanish university professors regarding the educational features of a set of business games. This information was gathered through a survey made, which was previously explained.

The MACBETH methodology was used for the handling of data introduced by Bana e Costa and Vansnick in 1994 and developed in the fall of 2002 trough MMACBETH software by the same authors with De Corte ${ }^{1}$ Such election responds to the fact that the previous technique requires exclusively qualitative judgment over the attractive differences within elements, to generate scores for the options of each criterion and to rank those criteria $[8,9]$.

The MACBETH method is based in the theory of the multi-attribute utility, developed by Keeney and Raiffa in 1976, in which each criterion indicated a partial description of the utility of the choices under a certain perspective. Such partial utilities, aggregated by a value function, will serve as reference to calculate the total utility, which will be taken as base to solve the problem.

\footnotetext{
${ }^{1}$ An introduction and demonstration of such software can be found at the web site: http://www.m-macbeth.com
} 
The implementation of this technique includes a series of phases that start with a first stage of structuring, in which will establish the criteria and the choices to be evaluated and their respective roles. In a second phase each option scores or preferences of attractiveness should be valued regarding to the different criterions based on a semantic scale of 7 categories: null, very weak, weak, moderate, strong, very strong, and extreme allowing that the evaluator expresses doubt [10]. From this scale derives the acronym MACBETH: "Measuring Attractiveness by a Category Based Evaluation Technique" (measure the attractiveness through a technique of evaluation based in categories). In this second stage a ranking of the criteria should be made. In the third and last phase, consistence of the evaluator judgment is verified, in a way they are introduced, the software suggests different possibilities in case of flimsiness. Once the qualitative judgment matrix is consistent, the software evolutions to a quantitative evaluation model that provides a scale of global scores that reflects the attractiveness of the choice in evaluation regarding the collection of all the criterions and that should be contrasted by the evaluator $[6,11,12]$.

Last, sensibility and roughness of the model results should be analyzed considering a key factor in the multicriteria methodology: data uncertainty.

The following Figure 1 shows the scheme that should be followed while implementing the MACBETH methodology:

Using the MACBETH methodology it will be possible to rank business games considering several features and criteria to determine the optimum simulator.

\section{Empirical Study and Results}

Once the reasons for the selection and main features of the MACBETH methodology were explained, is possible to implement such technique for the case object of study following the phases indicated previously.

These options will be, logically, the nine business simulators that were chosen in the surveys made for this study.

The criteria established are seven, and are the features that a business simulator should have in order to be effective from a pedagogical perspective. In Figure 2 the tree that the software provides and that collects such criterions and features can be observed.

Providing the 113 surveys and allowing one general answer from the software, the data of the professors is processed and calculating the mean of each one of the answers, obtaining the performance table shown in Figure 3, and that expresses the opinion of the professors regarding the pedagogical features of several business simulators considered.

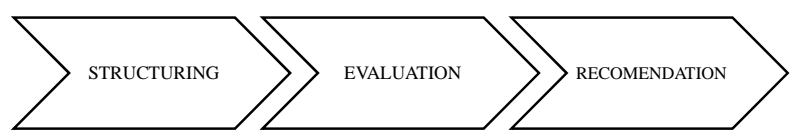

Figure 1. MACBETH methodology scheme. Source: Bana e Costa, De Corte y Vansnick (2005).

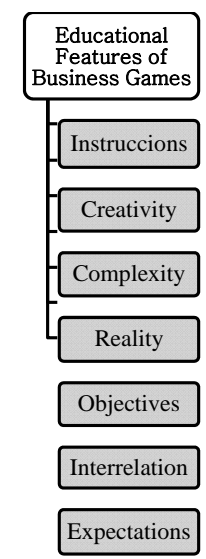

Figure 2. Tree of criterions selected for the election of a proper business simulator. Source: own preparation.

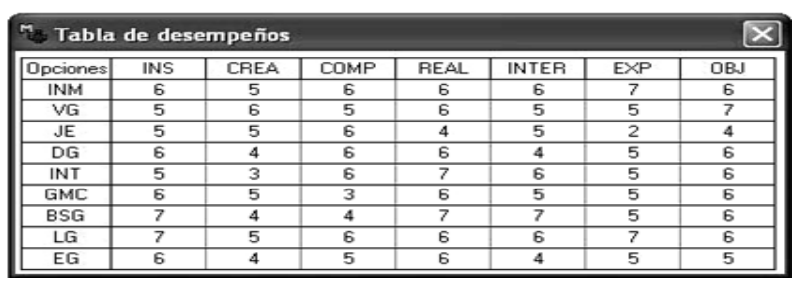

Figure 3. Performance Table. Source: own preparation from M-MACBETH software.

As explained previously, the criterions must be ranked. Nevertheless, considering that the objective of this research is to analyze which is the proper game from an educational approach, opting not to include judgments in the software considering that all the features of the game are equally important to see its pedagogical effectiveness increased; which accepts the scale proposed by $\mathrm{M}$ MACBETH.

Considering the previous an analysis of results can be made. Therefore if you observe Figures 4 it can be observed the ranking obtained is the following: 1). Management Laboratory (LG), 2). INTOPIA Mark 2000 (INM), 3). Business Strategy Game 8.0 (BSG), 4). Venture Game (VG), 5). INTOP (INT), 6). Manager Game (DG), 7). Global Marketing Competition (GMC), 8). Strategist Game (EG), 9. Game of the Executive (JE).

To state with certainty that the previous business simulators will have been selected by the professors in all cases, an analysis of robustness should be made to eliminate data uncertainty and assurance that the results are conclusive (observe Figure 5).

In the previous figures a global comparison of pair of 


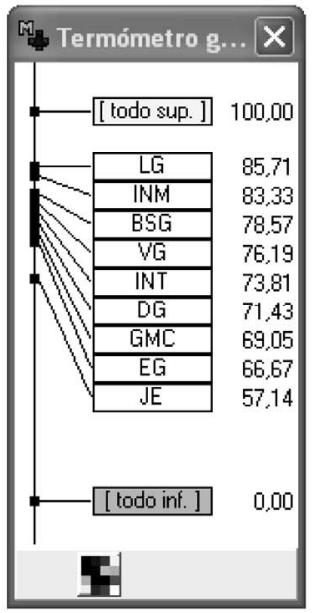

\begin{tabular}{|c|c|c|c|c|c|c|c|c|}
\hline \multicolumn{9}{|c|}{ Mabla de puntuaciones } \\
\hline Dpciones & Global & INS & CREA & COMP & REAL & INTER & EXP & DBJ \\
\hline INM & 83,33 & 83,33 & 66,67 & 83,33 & 83,33 & 83,33 & 100,00 & 83,33 \\
\hline VG & 76,19 & 66,67 & 83,33 & 66,67 & 83,33 & 66,67 & 66.67 & 100,00 \\
\hline JE & 57,14 & 66,67 & 66,67 & 83,33 & 50,00 & 66,67 & 16,67 & 50,00 \\
\hline DG & 71,43 & 83,33 & 50.00 & 83,33 & 83,33 & 50.00 & 66.67 & 83,33 \\
\hline INT & 73,81 & 66,67 & 33,33 & 83,33 & 100,00 & 83,33 & 66,67 & 83,33 \\
\hline GHC & 69,05 & 83,33 & 66,67 & 33,33 & 83,33 & 66,67 & 66,67 & 83,33 \\
\hline BSG & 78,57 & 100,00 & 50,00 & 50,00 & 100,00 & 100,00 & 66,67 & 83,33 \\
\hline LG & 85,71 & 100,00 & 66,67 & 83,33 & 83,33 & 83,33 & 100,00 & 83,33 \\
\hline EG & 66,67 & 83,33 & 50,00 & 66.67 & 83,33 & 50,00 & 66,67 & 66.67 \\
\hline [ todo sup. ] & 100,00 & 100,00 & 100,00 & 100,00 & 100,00 & 100,00 & 100,00 & 100,00 \\
\hline \begin{tabular}{|l|} 
[ todo inf. ] \\
\end{tabular} & 0,00 & 0,00 & 0,00 & 0,00 & 0,00 & 0,00 & 0,00 & 0,00 \\
\hline \multicolumn{2}{|c|}{ Pesos } & 0,1429 & 0,1429 & 0,1429 & 0.1429 & 0,1429 & 0,1429 & 0,1429 \\
\hline
\end{tabular}

Figures 4. Global thermometer and table of punctuations. Source: Own preparation from M-MACBETH software.

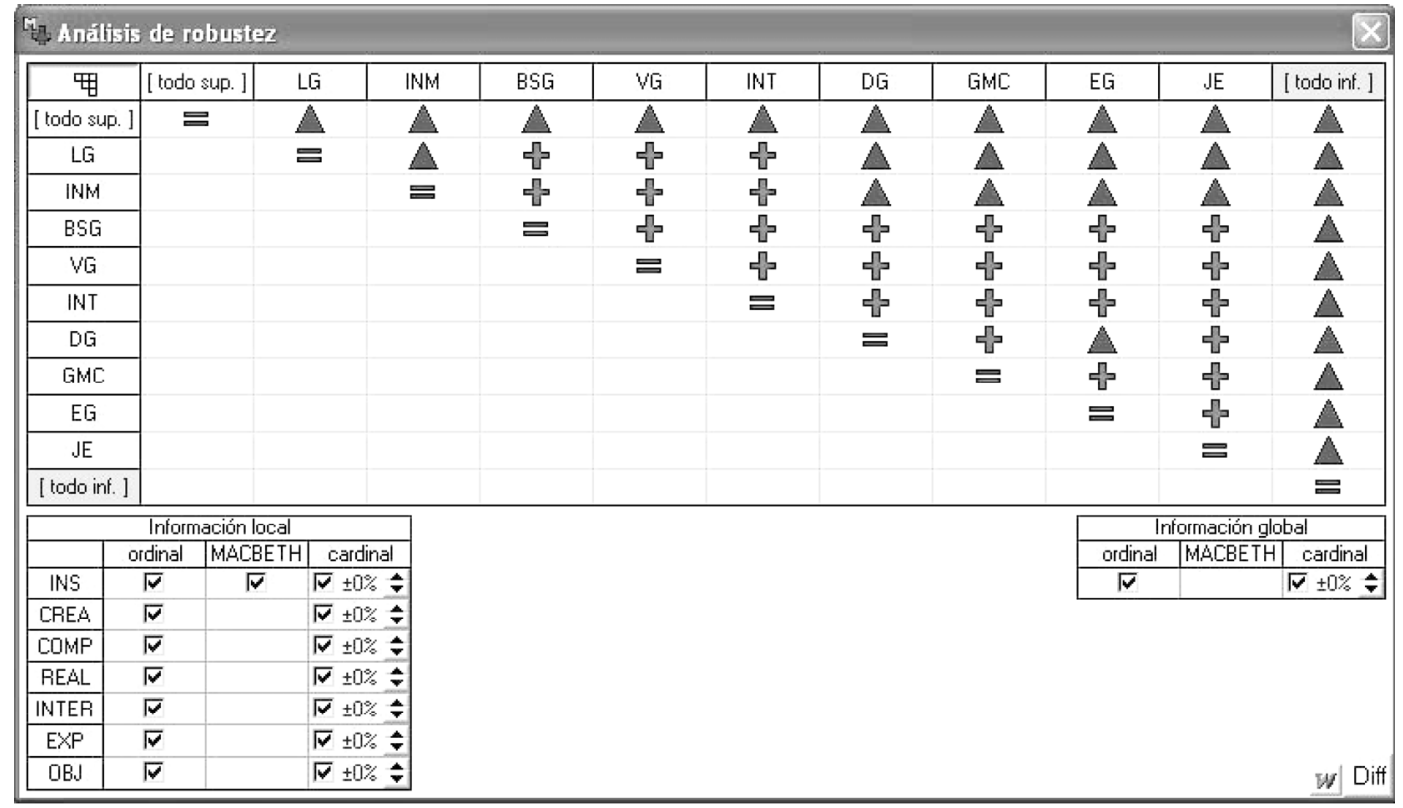

Figure 5. Robustness analysis. Source: Own preparation from M-MACBETH software.

choices are made and a relationship between them is showed. This way several symbols could arise: if "a dominates b" a triangle will come up in line a, and in column b; if "a is globally more attractive than b, considering the available information" a cross will show the relationship between these options, and in case this options are equivalent an equal sign will come up.

The case object of study proves that after the robustness analysis is made the simulation game Management Laboratories is a better choice in all cases, than the rest of the simulators considered.

\section{Conclusions}

The research made offers universities the possibility to employ the simulator, which between the ones analyzed, better satisfies educational needs. For this, MACBETH multi-criteria methodology was used, which was based on the qualitative judgment made by the professors who surveyed the features with which a business game must comply in order to be educational. And the game will allow to be organized precisely into a hierarchy that the nine simulators analyzed previously.

In this study pedagogical features were considered that, to the researchers judgment, could be valued objectively by the professor, which means that, those were involved with the game's plausibility and complexity, its capability to respond to setting expectations, the achievement of setting objectives a priori, the clarity of instructions, development of the student's creativity, and the level of expression in the interrelation between business subsys- 
tems.

At the sight of the results obtained, which could be concluded that the most valued simulator within the ones considered, is "Management Laboratory", for being the one that best adjusts to the educational needs of the Spanish university professors.

Although currently many business games exist, this research delimits the search for the optimum simulator, offering universities an efficient methodology that allows to save time and costs when selecting the most efficient simulator from a pedagogical perspective.

\section{REFERENCES}

[1] P. Straffin, “Game Theory and Strategy,” New Mathematical Library, New York, 2006.

[2] S. Castro, “Juegos, Simulaciones y Simulación-Juego y los entornos multimedia en educación Mito o Potencialidad? Revista de Investigación,” Universidad Pedagógica Experimental Libertador, Vol. 65, No. 13, 2008, pp. 223245.

[3] M. S. Y. Jong, J. Shang, F. Lee and J. H. M. Lee, "Harnesing Computer Games in Education," International Journal of Distance Education Technologies, Vol. 6, No. 1, 2008, pp. 1-9. http://dx.doi.org/10.4018/jdet.2008010101

[4] A. McManus and A. Fesinstein, "Implementation of Effective Experiential Learning Environments,” Simulation \& Gaming, Vol. 116, No. 1, 2009, pp. 230-235.

[5] C. Michelsen, "Eficacia de la Simulación,” II Simposio en E-Learning, Tecsup julio de, 2004. http://www.udec.cl/asinter/mostrar_datos.php?id=108904 3565

[6] M. Gutiérrez and M. S. Romero, "Experiential Learning: The Effectiveness in Distance Education,” Proceedings of INTED 2011 Conference, Valencia, 7-9 March 2011, pp. 4230-4238.

[7] C. Scalzo and L. Turner, "The Effect of Experimental Learning Experiences on Management Skills Acquisition," Developments in Business Simulation and Experiential Learning, Vol. 34, 2007, pp. 155-160.

[8] C. A. Bana e Costa and J. C. Vansnick, "MACBETH, an Interactive Path towards the Construction of Cardinal Value Functions,” International Transactions in Operational Research, Vol. 1, No. 4, 1994, pp. 489-500. http://dx.doi.org/10.1111/j.1475-3995.1994.00325.x

[9] C. A. Bana e Costa, J. M. De Corte and J. C. Vansnick, “M-MACBETH: User’s Guide,” 2005. www.m-macbeth.com

[10] R. Sánchez and C. A. Bana e Costa, "The MACBETH Approach for Multicriteria Evaluation of Rural Development Projects in Face of Cross-Cutting Issues,” Working Paper LSE OR 09.107, the London School of Economics and Political Science, 2009.

[11] J. A. Plata, M. E. Morales and M. A. Arias, "Impact of Managerial Games in Business Administration Programs as a Pedagogic Tool,” Revista de la Facultad de Ciencias Económicas: Investigación y Reflexión, Vol. 17, No. 1, 2009, pp. 77-94.

[12] R. L. Keeney and H. Raiffa, "Decisions with Multiple Objectives: Preferences and Value Tradeoffs,” Wiley, New York, 1996. 


\section{Appendix}

\section{ANNEX 1}

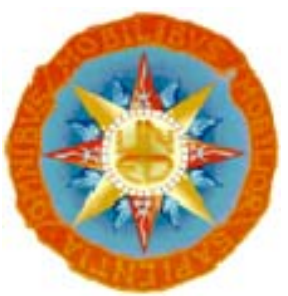

\section{Dear colleagues:}

The Group for Investigation of Simulation in Teaching (Grupo de Investigación de Simulación en la Enseñanza) (G.I.S.E) kindly requests your collaboration by completing the following survey regarding the business games you have implemented now a days in your teaching activities, with the objective of gathering a significant sample that will allow us to complete our research.

Thank you for participating.

University:

Game implemented:

Major:

Course:

Semester:

\section{INSTRUCTIONS}

This questionnaire is composed of two kinds of questions: open and closed. In the case of open questions is kindly requested for the answer to be precise. With closed questions just make an $\mathrm{X}$ in the answer you consider to be the most accurate, that is 1 for totally disagree and 7 for totally agree.

1. Game instructions are clear and allowing their accurate development.

\begin{tabular}{lllllll}
\hline 1 & 2 & 3 & 4 & 5 & 6 & 7 \\
\hline
\end{tabular}

2. Which is the optimum number of decisions that the student must make in order to understand the operation of the game?

3. The game allows students creativity.

\begin{tabular}{llllllll}
\hline 1 & 2 & 3 & 4 & 5 & 6 & 7 \\
\hline
\end{tabular}

4. Indicate the optimum number of participating teams in the simulation.
5. The grade of complexity of the game (regarding the number of measured variables) is accurate given the objectives to be achieved.

\begin{tabular}{llllllll}
\hline 1 & 2 & 3 & 4 & 5 & 6 & 7 \\
\hline
\end{tabular}

6. Value the business game utility as an educational tool in order to understand business reality.

\begin{tabular}{llllllll}
\hline 1 & 2 & 3 & 4 & 5 & 6 & 7 \\
\hline
\end{tabular}

7. Indicate the number of hours a student approximately needs for the study and implementation of the game.

8. Pedagogical objectives followed are being achieved within the development of the game.

$\begin{array}{lllllllll}1 & 2 & 3 & 4 & 5 & 6 & 7\end{array}$

9. The business simulator grasps the existing interrelation between several roles within the business.

\begin{tabular}{llllllll}
\hline 1 & 2 & 3 & 4 & 5 & 6 & 7 \\
\hline
\end{tabular}

10. Student expectations are being achieved with the implementation of the game.

\begin{tabular}{llllllll}
\hline 1 & 2 & 3 & 4 & 5 & 6 & 7 \\
\hline
\end{tabular}

